\title{
Size Control of Mixed Egg Yolk Phosphatidylcholine (EggPC)/Oleate Vesicles
}

\author{
Suparpun Chungcharoenwattana and Masaharu Ueno* \\ Faculty of Phamaceutical Sciences, Toyama Medical and Pharmaceutical University; 2630 Sugitani, Toyama 930-0194, \\ Japan. Received February 4, 2004; accepted June 30, 2004
}

The size distribution after addition of oleate surfactant to preformed Egg yolk phosphatidylcholine (EggPC) vesicles was investigated by gel filtration chromatography combining with dynamic light scattering. Phospholipid and oleate concentration, fluorescence intensity and size of the vesicles were measured for each elution fraction. The spontaneous vesiculation of oleate at $\mathrm{pH} 8.5$ was accelerated in the presence of preformed EggPC vesicles. The size distribution of newly formed vesicles was dependent on the preformed vesicular size. For example, oleate addition to large preformed vesicles $(230 \mathrm{~nm})$ resulted in altering of vesicles to both larger and smaller than preformed ones, while addition of oleate to small preformed vesicles $(50 \mathrm{~nm})$ led to the formation of only larger vesicles without exhibition of newly small vesicles. The combinations of gel filtration chromatography and dynamic light scattering could provide more detailed insight into the size change of newly formed vesicles.

Key words vesicle; gel chromatography; vesicle size; oleate; Egg yolk phosphatidylcholine (EggPC)

Incorporation of surfactants into vesicles lead to structural change of the vesicles followed by vesicle-to-micelle transition. The studies on this process have contributed to size regulation of vesicles prepared by removing detergent from detergent-phospholipid mixed micelles. ${ }^{1-4)}$ Fatty acids are one kind of surfactants whose properties are different from the others, that is, the fatty acids exist as micellar form above $\mathrm{pH}$ 9 but they can spontaneously form vesicles in the appropriate conditions. $^{5-9)}$

Luisi et al. have made interesting reports using dynamic light scattering, freeze fracture electron microscopy and cryotransmission electron microscopy as follows: when sodium oleate micellar solution was added into suspension of preformed oleate vesicles or 1-palmitoyl-2-oleoyl-sn-glycero-3phosphocholine (POPC) vesicles, the size of newly formed vesicles was similar to that of the preformed vesicles and preformed vesicles remarkably expedited the rate of new vesicles organization. ${ }^{10-13)}$ They called this phenomenon "matrix effect". However, normally average vesicular size in matrix effect was close to the size of preformed vesicles as far as the sizes were evaluated by quasielastic light scattering, which leading us to some misunderstanding of size distribution of newly formed vesicles.

To obtain more precise information relating size distribution with easier techniques, we started to study on this effect by the combination of gel filtration chromatography/quasielastic light scattering and found that the technique could provide more detailed insight into size distribution of newly formed vesicles without misapprehension as detection with mere dynamic light scattering technique. The study of this report deals with the effect of size variation of preformed vesicles as well as the influence of molar ratios EggPC/oleate on the size distribution of newly formed vesicles. Oleate solution was added to preformed egg yolk phosphatidylcholine vesicles with two original sizes followed by gel filtration on Sephacryl S-1000. The size of the vesicles and phospholipid and oleate concentrations of each fraction after gel filtration were analyzed. The results showed the final size distribution was somewhat dependent on the former vesicular size.

\section{Experimental}

Materials Egg yolk phosphatidylcholine (EggPC; purity of $\mathrm{PC}=98.8 \%$ ) was purchased from Nihon Yushi (Tokyo, Japan). Oleic acid sodium salt (98\%), boric acid $(99.5 \%)$, sodium chloride and calcein were purchased from Nacalai Tesque (Kyoto, Japan). All these materials were used without further purification.

Methods. Preparation of Liposomal Suspension Liposomes were prepared by the extrusion method as described below. A desired amount of phospholipids was dissolved in chloroform/methanol $(2: 1, \mathrm{v} / \mathrm{v})$ mixture, dried into a thin film on the wall of a glass tube under a stream of nitrogen. The remaining solvent was then removed under reduced pressure for more than $6 \mathrm{~h}$. The lipids were then resuspended in a borate buffer solution $(0.15 \mathrm{M}$ $\mathrm{NaCl}, 0.1 \mathrm{M}$ borate, $\mathrm{pH} 8.5$ ) containing calcein by vortexing. The lipid mixtures were freeze-thawed 5-times and extruded 10-times through two stacked $400 \mathrm{~nm}$-defined pore polycarbonate filters (Nucleopore, Costar Co., U.S.A.) at room temperature. The resulting vesicle size was roughly $230 \mathrm{~nm}$.

Small unilamellar vesicles were prepared with ultrasonic generator. The MLV suspension was sonicated four times for 20 min with a rest times for $10 \mathrm{~min}$. Titanium fragments and multilamellar aggregate were removed by centrifugation at $50000 \mathrm{rpm}$ for $1 \mathrm{~h}$ at $4{ }^{\circ} \mathrm{C}$. The top phase was separated from the bottom phase and size measurement was performed. Thus fairly monodisperse vesicles with average sizes of $50-60 \mathrm{~nm}$ were prepared.

Preparation of Mixed EggPC/Oleate Liposomes The stock solution of $80 \mathrm{~mm}$ sodium oleate dissolved in purified water $(\mathrm{pH} 10.25$ ) was prepared. A defined amount of sodium oleate was added into a known amount of liposome suspension of two different sizes $(230$ or $50 \mathrm{~nm}$ ) and then gently mixed with a stirrer for $1 \mathrm{~min}$. A buffer solution $(0.15 \mathrm{M} \mathrm{NaCl}, 0.1 \mathrm{~m}$ borate, $\mathrm{pH} 8.5)$ was used as control. The liposome suspensions were run through gel filtration chromatography before and $100 \mathrm{~min}$ after oleate addition. The final molar ratios of EggPC to sodium oleate were $1: 2,1: 1$ and $2: 1$. The experiments were run at $25^{\circ} \mathrm{C}$.

Gel Exclusion Chromatography Fractionation of the phospholipid vesicles by gel filtration was performed as described by Reynolds et al. ${ }^{14)} \mathrm{A}$ column $(1 \mathrm{~cm} \times 48 \mathrm{~cm})$ consisting of packing material (Sephacryl S-1000 superfine with bead diameter ranging from 40 to $105 \mu \mathrm{m}$, average $65 \mu \mathrm{m}$ ) was equilibrated with the borate buffer $(0.15 \mathrm{M} \mathrm{NaCl}, 0.1 \mathrm{~m}$ borate, $\mathrm{pH} 8.5)$. The EggPC suspension and the mixture of EggPC/oleate suspension with $20 \mu \mathrm{M}$ calcein $(200 \mu 1)$ were applied to the column and eluted with borate $/ \mathrm{NaCl}$ buffer. Routinely, $0.67 \mathrm{ml}$ fractions were collected in glass tubes using automatic fraction collector. The gel filtration fractions were sequentially subjected to the measurements of phospholipid concentrations as phosphorus according to the method of Ames, ${ }^{15)}$ sizes and fluorescence intensities.

Determination of Oleic/oleate Concentration The amount of oleic/oleate in the formulations of EggPC/oleate at molar ratio $1: 2$ (preformed vesicular size $50 \mathrm{~nm}$ ) was determined by high-performance liquid chromatography (HPLC). The HPLC condition was modified from the method of Schmitt M. and Lehr M. ${ }^{16)}$ The separations were carried out on a Nucleosil $100 \mathrm{C}_{18}$ analytical column $(150 \mathrm{~mm} \times 3.2 \mathrm{~mm}$, I.D., particle size 
$5 \mu \mathrm{M})$ protected with a Waters $\mathrm{C}_{18}$ guard column. $20 \mu \mathrm{l}$ of each sample was injected onto the HPLC system. The slightly unclear fractions were diluted with methanol before injection. The mobile phase consisted of acetonitrile-water-phosphoric acid (85\%) $(80: 20: 0.1, \mathrm{v} / \mathrm{v} / \mathrm{v})$ and was filtered before use. The chromatographic system employed a flow-rate of $0.4 \mathrm{ml} / \mathrm{min}$ and a spectrophotometric detection at $200 \mathrm{~nm}$.

Turbidity Measurement Turbidity measurement was performed with a UV-160A spectrophotometer (Shimadzu) at $400 \mathrm{~nm}$ using a quartz cell with a path length of $1 \mathrm{~cm}$. The final volume of mixture was $1 \mathrm{ml}$ and the final molar ratio of EggPC/oleate was 1:99. The size of preformed EggPC vesicles was $230 \mathrm{~nm}$. Progression of turbidity upon time was studied to observe spontaneous process.

Quasielastic Light Scattering Measurement The vesicular sizes were determined with quasielastic light scattering using a LPA 3000/3100 laser particle analyzer (Otsuka electronics, Japan) at scattering angels $90^{\circ}$.

Fluorescence Intensity Measurement The $100 \mu \mathrm{l}$ aliquots of the eluted fractions were diluted with $2 \mathrm{ml}$ buffer before each measurement. Fluorescence measurements were carried out with a RF-5000 fluorescence spectrophotometer (Shimadzu) equipped with a magnetic stirrer at an excitation wavelength of $490 \mathrm{~nm}$ and emission wavelength of $520 \mathrm{~nm}$

\section{Results}

Turbidity as a Function of Time The time progress of turbidity after the oleate addition to borate buffer $\mathrm{pH} 8.5$ and preformed vesicles is exhibited in Fig. 1. The oleate addition to preformed vesicles has an influence on the production of mixed vesicles. Small amount of preformed vesicles can accelerate vesicle growth during the first $10 \mathrm{~min}$. The size of oleate vesicles in borate buffer was in the range of 450 to $800 \mathrm{~nm}$. However, the addition of oleate into preformed EggPC vesicle suspension resulted in formation of mixed vesicles with rather narrow size distribution (in the range of $195-250 \mathrm{~nm}$ ). These particle sizes were measured after the addition of oleate in borate buffer or in preformrd vesicle suspension at interval time presented in Fig. 1. The results indicated that the preformed vesicles influenced vesicle formation rate and the size of the newly formed vesicles.

Gel Exclusion Chromatography Figure 2 showed the elution patterns of preformed EggPC vesicles with the size of 230 or $50 \mathrm{~nm}$ and EggPC/oleate $(1: 2)$ vesicles formed after addition of oleate micelles to the preformed vesicles. The gel
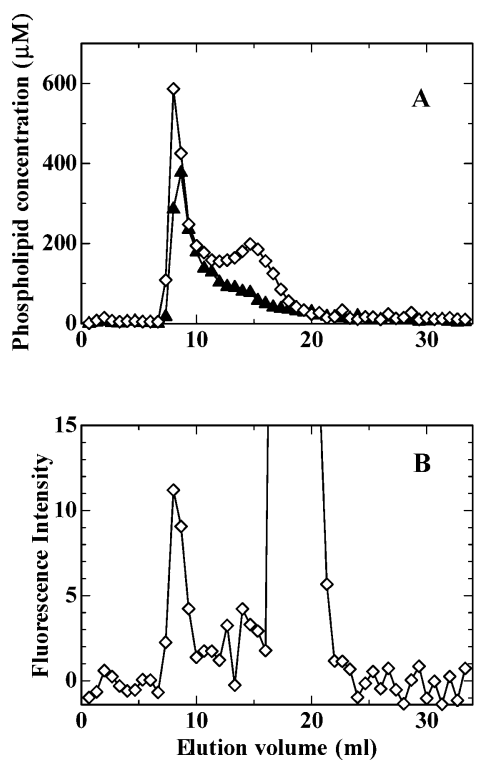

filtration profile of EggPC vesicles revealed only a single peak whereas EggPC/oleate vesicles exhibited two peaks, one is eluted earlier at lower elution volume and the other is a small peak at higher elution volumes. This indicates existing of large and small vesicles after oleate addition to preformed vesicles. Although these two peaks are less well separated, the new small peak reflects newly created vesicles with smaller size. The mixed EggPC/oleate vesicle dispersion presented an elution profile of calcein with three peaks (Fig. 2B). The first peak, which is overlapping on the first peak of phospholipid chromatogram (Fig. 2A), remarks the calcein-entrapping large vesicles. The second one at the elution volume near $15 \mathrm{ml}$ is a peak corresponding newly small vesicles and the third one refers to free calcein molecules. In the case of preformed EggPC vesicules with a size of $50 \mathrm{~nm}$, the elution profiles of EggPC vesicles and EggPC/oleate vesicles were nearly superimposed (Fig. 2C). Elution patterns of phospholipid and oleate were similar with each other, indicating the incorporation of oleate to EggPC vesicles (Fig. 3).

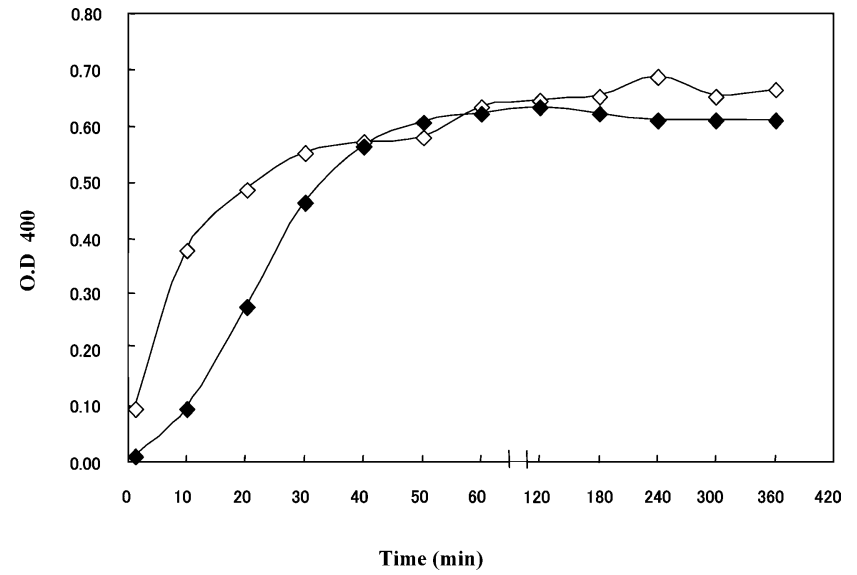

Fig. 1. Time Courses of Turbidity of Preformed EggPC/Oleate (1:99) Vesicles $(\diamond)$ and Oleate Vesicles $(\diamond)$ in the Borate Buffer

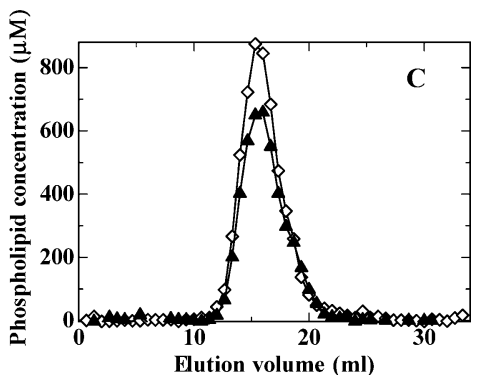

Fig. 2. Elution Profiles of Phospholipid Concentration and Fluorescence Intensity of EggPC and EggPC/Sodium Oleate (1:2) Vesicles

Size of preformed EggPC vesicles: A-B, $230 \mathrm{~nm} ; \mathrm{C}, 50 \mathrm{~nm}$. $625 \mu 1$ of sodium oleate $(80 \mathrm{~mm})$ was added to $1.875 \mathrm{ml}$ of preformed vesicle suspension (EggPC: $13.33 \mathrm{~mm})$. $\longrightarrow$, EggPC; $\diamond$, EggPC/sodium oleate $(1: 2)$. 
Figures 4 and 5 depicted the gel filtration profiles of EggPC and oleate-containing EggPC vesicular dispersions, whose EggPC/oleate molar ratios are $1: 1$ and $2: 1$, respectively. The oleate additions to preformed EggPC vesicles having sizes of $230 \mathrm{~nm}$ (Figs. 4A, 5A) showed the sharp peak with a shoulder. These patterns represent the mixture of large and newly small vesicles. At the preformed vesicles of $50 \mathrm{~nm}$, the EggPC and the mixed EggPC/oleate dispersion profiles of two molar ratios at $1: 1$ and $2: 1$ (Figs. 4B, 5B) are not different from the previous results (Fig. 2C).

The correlations of phospholipid concentrations versus sizes $(\mathrm{nm})$ of oleate-free EggPC vesicles and oleate-containing EggPC, of which original sizes were 230 and $50 \mathrm{~nm}$, were depicted on Figs. 6 and 7 respectively. As shown in Fig. $6 \mathrm{~A}$, the main population of EggPC/oleate $(1: 2)$ vesicles, which original average size was $230 \mathrm{~nm}$, shifted toward smaller vesicles around $150-180 \mathrm{~nm}$ and some part of vesicles become bigger ones. The size distribution profile for EggPC/oleate $(1: 1)$ vesicles (Fig. 6B) or EggPC/oleate

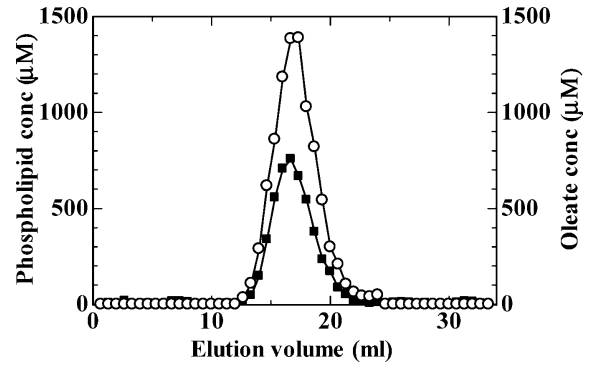

Fig. 3. Elution Profile of EggPC/Sodium Oleate $(1: 2)$

The size of preformed EggPC vesicles was $50 \mathrm{~nm}$. — tion; - $\bigcirc-$, oleate concentration.
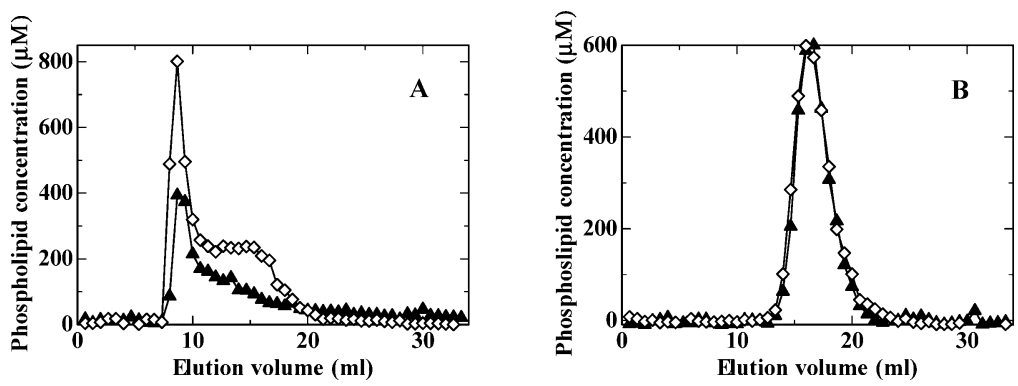

Fig. 4. Gel Filtration Curves of EggPC and EggPC/Sodium Oleate $(1: 1)$

Size of preformed EggPC vesicles: A, $230 \mathrm{~nm}$; B, $50 \mathrm{~nm} .312 \mu 1$ of sodium oleate $80 \mathrm{~mm}$ was added to $2.188 \mathrm{ml}$ of preformed vesicle suspension (EggPC: $11.426 \mathrm{~mm}$ ). $\triangle$ — EggPC; $\prec$ EggPC/sodium oleate $(1: 1)$
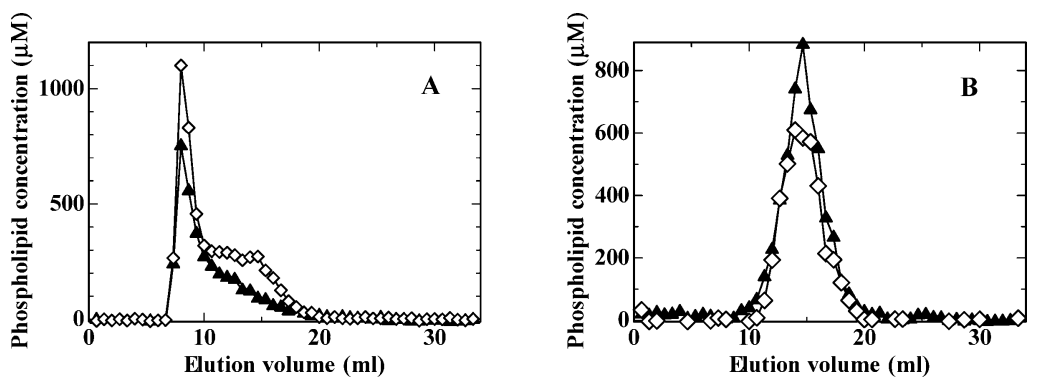

Fig. 5. Gel Filtration Curves of EggPC and EggPC/Sodium Oleate (2:1) Size of preformed EggPC vesicles: A, $230 \mathrm{~nm}$; B, $50 \mathrm{~nm} .312 \mu 1$ of sodium oleate $80 \mathrm{~mm}$ was added to $2.188 \mathrm{ml}$ of preformed vesicle suspension (EggPC: $22.852 \mathrm{~mm}$ ). $\neg$ - EggPC; $\prec-$, EggPC/sodium oleate $(2: 1)$. 

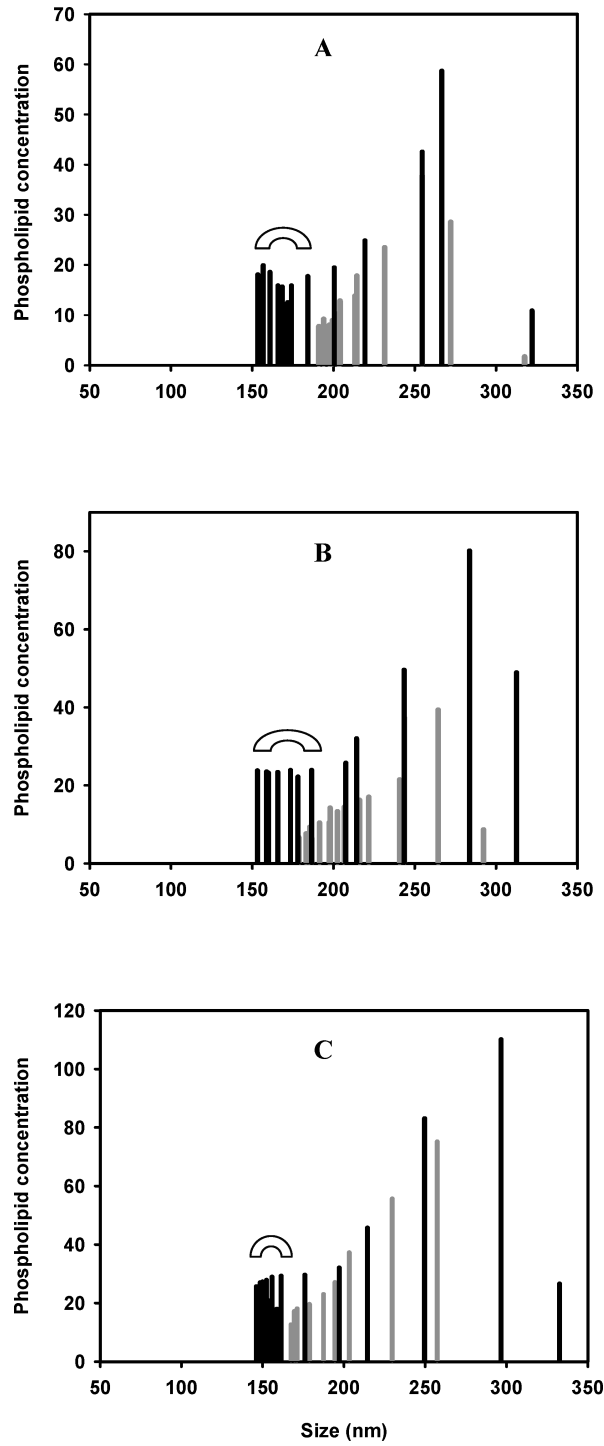

Fig. 6. The Relationship between Size and Phospholipid Concentrations before and after Oleate Addition to $230 \mathrm{~nm}$ EggPC Vesicles

EggPC/oleate molar ratio; A, 1:2; B, 1:1; C, 2:1. EggPC vesicles; EggPC/sodium oleate vesicles. The mark $(\curvearrowright)$ shows size range of main population of newly formed vesicles.

matography with Sephacryl S-1000, which has been used for fractionation of lipid vesicles and known to be its exclusion limit of $30-300 \mathrm{~nm}^{.14,18-23)}$

The results demonstrated that original size of preformed EggPC vesicles had an influence on the size of newly formed vesicles. After fractionation of the mixed vesicles (refer to $230 \mathrm{~nm}$ size of preformed vesicles) through gel column, one peak with a shoulder was observed. The calcein-entrapping small vesicles shown in Fig. 2B could not markedly point to the newly small vesicles due to weak fluorescence intensity. This weak intensity might be possibly due to small entrapping amount of such small vesicles and/or the leakage of calcein from the vesicles. However, the shoulder peak of different molar ratios of EggPC and oleate (Figs. 2A, 4A, 5A) could indicate the vesiculation of newly small vesicles. On the other hand, when the sizes of mixed samples were measured by dynamic light scattering before applying on gel column, the measured average size was closed to the size of preformed vesicles. Even though the appearance of newly small
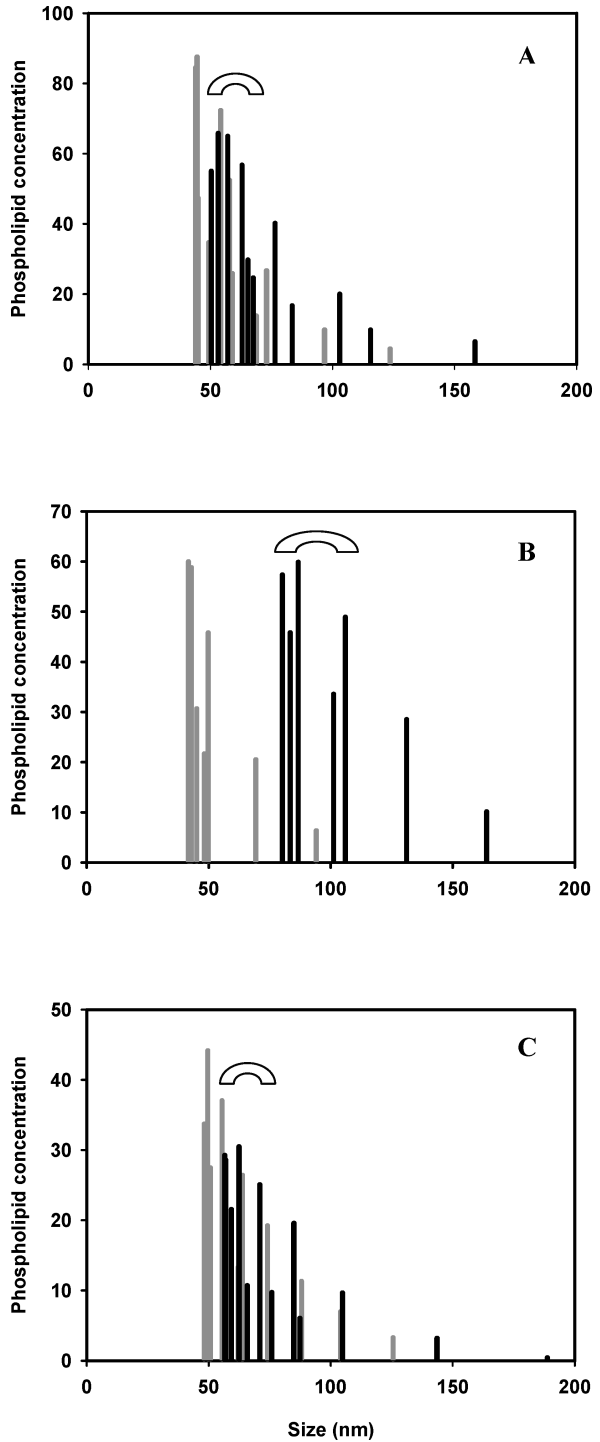

Fig. 7. The Relationship between Size and Phospholipid Concentrations before and after Oleate Addition to $50 \mathrm{~nm}$ EggPC Vesicles

EggPC/oleate molar ratio; A, 1:2; B, 1:1; C, 2:1. , EggPC vesicles; EggPC/sodium oleate vesicles. The mark ( $\curvearrowright$ ) shows size range of main population of newly formed vesicles.

\section{Mechanism}

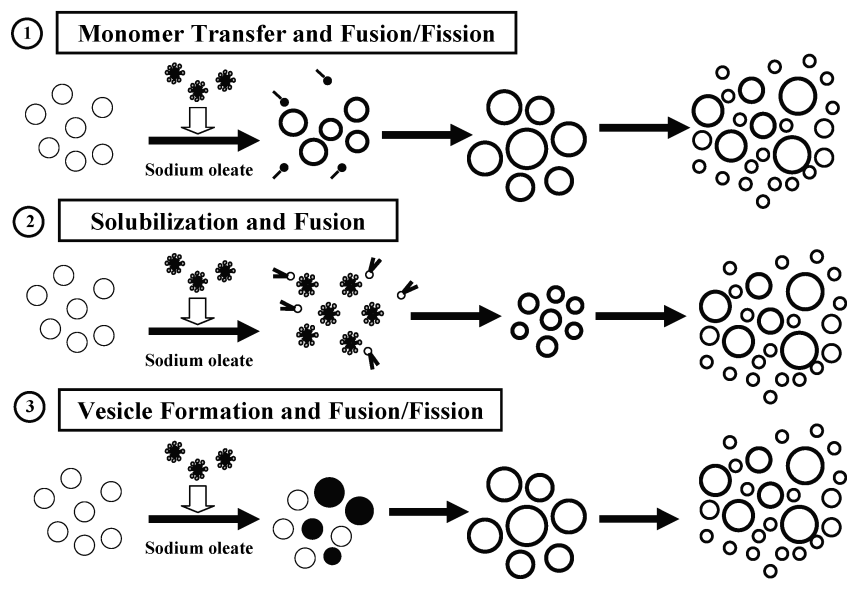

Fig. 8. Possible Models for the Formation of Oleate/EggPC Mixed Vesicles in the Presence of Preformed EggPC Vesicles 
vesicles could be observed in the pattern of some particle size distribution, the measured average sizes were still closed to the preformed vesicular size. On the other hand the result of our experiment by fractionation of samples with gel filtration before size measurement can clearly display the size distribution of matrix effect as shown in Fig. 6. The first peak referred to the larger size of newly formed vesicles was distributed in the range of $200-335 \mathrm{~nm}$ (elution volume at $7.33-10.00 \mathrm{ml}$ ) and the shoulder peak referred to the smaller size of newly formed ones was in the range of 150 $180 \mathrm{~nm}$ (elution volume at $10.00-14.67 \mathrm{ml}$ ).

In contrast to the case of large preformed vesicles, the gel filtration profiles of small preformed vesicles (Figs. 2C, 4B, $5 \mathrm{~B})$ showed that there was no apparent change after oleate addition. However, particle size distribution patterns in Fig. 7 reveal new vesicles with a little larger size than preformed ones. Our results were different from the finding obtained by Blochliger et al. ${ }^{10)}$ They showed that hydrolysis of oleic anhydride in the presences of preformed vesicles of $50 \mathrm{~nm}$-size led to newly formed vesicles within the size range of 50 $100 \mathrm{~nm}$, together with a decreasing of vesicles in the 20 $50 \mathrm{~nm}$ region. This different result might be due to the lipid composition of preformed vesicles. The matrix effect on the newly formed vesicles may depend on the preformed vesicles. The addition of oleate micelle to large preformed vesicles caused the formation of larger and smaller vesicles while oleate addition to small preformed ones led to the formation of only larger vesicles. The interesting point is that the size of newly formed vesicles was not much larger than that of preformed vesicles and the size was much smaller than that of pure oleate vesicles.

Since fatty acids can bind rapidly and quantitatively to the phospholipid vesicles, ${ }^{24-27)}$ the newly formed vesicles can be expected to be composed of EggPC and oleate. The present work showed that oleate is an integral part of the newly formed vesicles, as the oleate pattern in the elution profile of the gel chromatography was very similar to phospholipid pattern (Fig. 3).

Quasielastic light scattering is not good enough to detect size distribution in polydisperse suspension. Especially, it is sensitive to detect large particles more than small ones. ${ }^{13,28)}$ In order to obtain creditable results, samples fractionation according to size prior to quasielastic light scattering measurement is recommended. ${ }^{19)}$ In this report we have shown that the fractionation by gel chromatography on Sephacryl S1000 before dynamic light scattering measurement gives useful information for size distribution of vesicles although subjects to limitation of effective size range being $30-300 \mathrm{~nm}$.

To elucidate size change of newly formed vesicles after addition of oleate to preformed vesicles next 3 possible mechanisms were assumed (Fig. 8). One is oleate transfer from oleate micelles to preformed EggPC vesicles followed by fusion/fission between the mixed vesicles. Next is partial solubilization of preformed EggPC vesicles by oleate micelles followed by rapid vesiculation of EggPC-containing oleate micelles. The last is that oleate micelles form vesicles independently of preformed vesicles, followed by fusion or lipid exchange between oleate vesicles and EggPC vesicles. The last mechanism might hardly occur because of time consuming of oleate vesicle formation without preformed vesicles. Therefore, the first and second one may be reasonable mechanism, but it is not clear from present experimental data which mechanism dominates the other.

In conclusion, this study demonstrated that spontaneous vesiculation of oleate at $\mathrm{pH} 8.5$ was accelerated in the presence of only $1 \%$ preformed EggPC vesicle and gel chromatography technique provided mixed vesicle formation with both larger and smaller sizes than the preformed ones. The size of preformed vesicles influenced the size of newly formed vesicles, but the effect of the molar ratio of preformed $\mathrm{EggPC} /$ added oleate on the size distribution of newly formed vesicles was rather small in our experimental conditions. The study also provided detailed information on a feasible estimation of size distribution of newly formed vesicles that depended on the preformed vesicles. The combination of gel exclusion chromatography and dynamic light scattering can provide detailed information about size changeability of matrix effect while mere dynamic light scattering is unable to accurately characterize this phenomenon.

\section{References}

1) Sun C., Ueno M., Colloid Polym. Sci., 278, 855-863 (2000).

2) Bernheim-Groswasser A., Zana R., Talmon Y., J. Phys. Chem. B, 104, 12192-12201 (2000).

3) Ueno M., Hirota N., Kashiwagi H., Sagasaki, Colloid Polym. Sci., 282, $69-75$ (2003).

4) Rossi S., Karlsson G., Martini G., Edwards K., Langmuir, 19, 56085617 (2003).

5) Hargreaves W. R., Deamer D. W., Biochemistry, 17, 3759-3768 (1978).

6) Apel C. L., Deamer D. W., Mautner M. N., Biochim. Biophys. Acta, 1559, $1-9$ (2002).

7) Walde P., Wick R., Fresta M., Mangone A., Luisi P. L., J. Am. Chem. Soc., 116, 11649-11654 (1994).

8) Edwards K., Silvander M., Karlsson G., Langmuir, 11, 2429-2434 (1995).

9) Hauser H., Gains N., Biochemistry, 79, 1683-1687 (1982).

10) Blochliger E., Blocher M., Walde P., Luisi P. L., J. Phys. Chem. B, 102, 10383-10390 (1998).

11) Lonchin S., Luisi P. L., Walde P., Robinson B. H., J. Phys. Chem. B, 103, 10910-10916 (1999).

12) Berclaz N., Muller M., Walde P., Luisi, P. L., J. Phys. Chem. B, 105, 1056-1064 (2001)

13) Berclaz N., Blochliger E., Muller M., Luisi P. L., J. Phys. Chem. B, 105, 1065-1071 (2001).

14) Reynolds J. A., Nozaki Y., Tanford C., Anal. Biochem., 130, 471-474 (1983).

15) Ames B. N., Methods Enzymol., 8, 115-117 (1966).

16) Schmitt M., Lehr M., J. Chromatogr. B, 783, 327-333 (2003).

17) Cistola D. P., Hamilton J. A., Jackson D., Small D. M., Biochemistry, 27, 1881-1888 (1988)

18) Nozaki Y., Lasic D. D., Tanford C., Reynolds J. A., Science, 217, 366-367 (1982).

19) Schurtenberger P., Hauser H., Biochim. Biophys. Acta, 778, 470-480 (1984).

20) Ueno M., Tanford C., Reynolds J. A., Biochemistry, 23, 3070-3076 (1984).

21) Feldman D. A., Rounsifer M. E., Weinhold P. A., Biochim. Biophys. Acta, 429, 429-437 (1985).

22) Cohen D. E., Carey M. C., J. Lipid Res., 31, 2103-2112 (1990).

23) Sriwongsitanont S., Ueno M., Chem. Pharm. Bull., 50, 1238-1244 (2002).

24) Kamp F., Hamilton J. A., Proc. Natl. Acad. Sci. U.S.A., 89, 11367 11370 (1992)

25) Kamp F., Zakim D., Zhang F., Noy N., Hamilton J. A., Biochemistry, 34, 11928-11937 (1995).

26) Hamilton J. A., J. Lipid Res., 39, 467-481 (1998).

27) Thomas R. M., Baici A., Werder M., Schulthess G., Hauser H., Biochemistry, 41, 1591-1601 (2002).

28) Egelhaaf S. U., Wehrli E., Muller M., Adrian M., Schurtenberger P., J. Microsc., 184, 214-228 (1996). 